\title{
Effect of a Taped Filter Mask on Perceived Breathlessness, Heart Rate, Lactate and Oxygen Saturation During a Graded Exercise Test
}

Hoi Lam Ng

Technical University of Munich

Johannes Trefz

Technical University of Munich

Martin Schönfelder

Technical University of Munich

Henning Wackerhage ( $\nabla$ henning.wackerhage@tum.de)

Technical University of Munich

\section{Research Article}

Keywords: SARS-CoV-2, COVID-19, face masks, exercise

Posted Date: June 29th, 2021

DOl: https://doi.org/10.21203/rs.3.rs-654495/v1

License: (9) This work is licensed under a Creative Commons Attribution 4.0 International License. Read Full License 


\section{Abstract}

Background: Face masks are an effective, non-pharmacological strategy to reduce the transmission of Severe Acute Respiratory Syndrome Coronavirus-2 (SARS-CoV-2) and other pathogens. However, it is a challenge to keep masks sealed during exercise, as ventilation can increase from 5-10 L/min at rest to up to $200 \mathrm{~L} / \mathrm{min}$ so that masks may be blown away from the face. To reduce leakage e.g. during exercise, a face mask was developed that is taped onto the face. The aim of this study was to investigate during a graded cycle ergometry test the effect of a taped mask on the perception of breathlessness, heart rate, lactate, and oxygen saturation when compared to a surgical mask and no mask.

Methods: Four trained and healthy males and females each ( $n=8$ in total) performed incremental cycle ergometer tests until voluntary exhaustion under three conditions: (1) No mask/control, (2) surgical mask or (3) taped mask. During these tests, we measured perception of breathlessness, heart rate, the concentration of blood lactate and peripheral oxygen saturation and analysed the resultant data with one or two-way repeated measures ANOVAs. We also used a questionnaire to evaluate mask comfort and analysed the data with paired t-tests.

Results: When compared to wearing no mask, a taped face mask significantly reduces the maximal workload in a graded exercise test by $12 \pm 6 \%(p=0.001)$. Moreover, with a taped face mask, subjects perceive severe breathlessness at $12 \pm 9 \%$ lower workload $(p=0.012)$ and oxygen saturation at $65 \%$ of the maximal workload is $1.5 \%$ lower $(\mathrm{p}=0.018)$ when compared to wearing no mask. Heart rate and the concentration of lactate were not significantly different at any workload. When compared to wearing a surgical mask, wearing a taped face mask has a significantly better wearing comfort $(p=0.038)$, feels better on the skin $(p=0.004)$, there is a lower sensation of moisture $(p=0.026)$ and wearers perceive that less heat is generated $(p=0.021)$. We found no sex/gender differences for any parameters.

Conclusions: A taped mask is well tolerated during light and moderate exercise intensity but reduces maximal exercise capacity.

\section{Background}

Since December 2019, the global coronavirus disease 2019 (COVID-19) pandemic has fundamentally changed the way we live, travel and exercise (1). By the end of May 2021, there were 170 millions of confirmed cases of COVID-19 globally, and over 3 million deaths have been recorded (2). COVID-19 is caused by the Severe Acute Respiratory Syndrome Coronavirus-2 (SARS-CoV-2) which is a respiratory virus that can be transmitted through droplets, aerosol and SARS-CoV-2-contaminated surfaces $(3,4)$. Breathing, speaking, coughing and sneezing can produce droplets and aerosols (5-7) and SARS-CoV-2 can remain active for hours in aerosol (8).

The COVID-19 pandemic and measures to contain its spread have also affected exercise, sport and sporting events (9). In relation to this, the arguably most consequential decision was to postpone the 2020 Tokyo Olympic Games to 2021. This was the first time in history that Olympic Games were 
cancelled due to a health issue (10). In addition, governments banned competitive sports and closed sporting facilities such as gyms and swimming pools. Not only did this negatively affect the sports economy but it also altered physical activity levels (9).

Face masks are an effective, non-pharmacological strategy to reduce SARS-CoV-2 transmissibility and infection (11-18). Face masks can also prevent infections during sport, as Watson et al. (19) reported that the use of face masks was associated with decreased COVID-19 incidence during sports. The question arises, however, whether different types of face masks have negative effects on ventilation, cardiovascular function and metabolism. This issue has been addressed in publications that have measured the effects of different types of face mask on hemodynamic, cardiopulmonary, and metabolic parameters during exercise $(17,20-29)$. Some studies found that wearing a face mask during exercise reduced cardiopulmonary function or exercise performance $(7,23,26,27)$. However, other studies showed that wearing a face mask does not hinder performance or cardiorespiratory function $(20,21,28,29)$. These, diverse results may result from different study designs and methods, such as constant or progressive load protocols.

A limitation of conventional face masks is that air may increasingly escape unfiltered when ventilation increases from $\approx 5-10 \mathrm{~L} / \mathrm{min}$ at rest to over $100 \mathrm{~L} / \mathrm{min}$ in untrained subjects (30) and up to $200 \mathrm{~L} / \mathrm{min}$ e.g. in highly trained rowers (31-33). To address the issue of leakage of unfiltered air at high levels of ventilation, a taped face mask was developed, where a "filtering facepiece 2" (FFP2) filter - combined with a laminar KinesioTape - is taped onto the face.

Here, we investigate during graded exercise tests the effect of this taped filter mask on the perception of breathlessness (dyspnoea scale), metabolism (lactate), cardiac and circulatory function (heart rate, blood oxygenation) and exercise performance during a graded exercise test when compared to a surgical mask and no mask. Specifically, we aimed to answer three research questions (34):

1. Up to what intensity can subjects exercise with a taped face mask without the perception of major breathlessness and/or a stable drop in the peripheral capillary oxygen saturation $\left(\mathrm{SpO}_{2}\right)$ to below $80 \%$ ?

2. How does a taped mask affect heart rate and the concentration of blood lactate during a graded cycle ergometer test when compared to a surgical mask and no mask?

3. How comfortable is an adhesive mask during a graded cycle ergometer test when compared to a surgical mask?

\section{Methods}

This study was approved by the ethical committee of the Technical University of Munich (Approval No. $584 / 20 \mathrm{~S}$ ). Four trained and healthy males and females each ( $\mathrm{n}=8$ in total) were recruited and completed the study (Table 1). 
Table 1

Physical characteristics of participants. $S D=$ Standard deviation

\begin{tabular}{|lllll|}
\hline \multicolumn{3}{|c}{ Male $(\mathbf{n = 4 )}$} & \multicolumn{3}{c|}{ Female $(\mathbf{n = 4 )}$} \\
\hline & Mean \pm SD & Range & Mean \pm SD & Range \\
\hline Age (year) & $25.3 \pm 3.6$ & $22-30$ & $23.8 \pm 3.2$ & $19-26$ \\
\hline Height $(\mathrm{cm})$ & $187 \pm 3.4$ & $184-192$ & $169 \pm 12.5$ & $152-182$ \\
\hline Weight $(\mathrm{kg})$ & $82 \pm 7.5$ & $71-88$ & $67.8 \pm 6.2$ & $62-76$ \\
\hline
\end{tabular}

The study had three study conditions:

1. no mask control,

2. commercially available surgical face mask (Fig. 1A) and a

3. taped filter mask (Fig. 1B)

The characteristics of the two face masks are described in Table 2. For taped masks, male participants used the larger size, whereas female participants used the smaller size.

Table 2

Physical characteristics of the masks

\begin{tabular}{|c|c|c|c|c|}
\hline $\begin{array}{l}\text { Mask } \\
\text { Type }\end{array}$ & $\begin{array}{l}\text { Size } \\
(\mathrm{cm})\end{array}$ & $\begin{array}{l}\text { Product name } \\
\text { - Materials }\end{array}$ & Weight & $\begin{array}{l}\text { Thickness } \\
(\mathrm{mm})\end{array}$ \\
\hline $\begin{array}{l}\text { Taped } \\
\text { Mask }\end{array}$ & $\begin{array}{l}15 \mathrm{x} \\
12 \\
16 \mathrm{x} \\
12.8\end{array}$ & $\begin{array}{l}\text { The Proper Mask } \\
\text { - Tape patch is comparable to KinesioTape (Suzhou } \\
\text { MedSport Products Co., LTD.) and is combined with filter- } \\
\text { fleece made of Premium-Protect } 囚 \text { Filtration Layer FFP2 } \\
\text { (Textilmacher GmbH; Munich, GER) }\end{array}$ & $\begin{array}{l}44 \\
\mathrm{~g} / \mathrm{m}^{2}\end{array}$ & 0.46 \\
\hline $\begin{array}{l}\text { Surgical } \\
\text { Mask }\end{array}$ & $\begin{array}{l}17.5 \\
x \\
9.5\end{array}$ & $\begin{array}{l}\text { Moon-Valley Face Mask } \\
\text { - Non-woven fabric (70\%), Melt-blown fabric (30\%) }\end{array}$ & $3.5 \mathrm{~g}$ & 0.4 \\
\hline
\end{tabular}

Study protocol. All participants underwent a medical fitness examination at the start of the study to ensure they had no contraindication to exercise testing and to check for inclusion criteria. After passing medical screening, subjects participated in three graded cycling tests on three different days. Tests were at least 24 hours apart to ensure full recovery in-between tests. For each participant, all three tests were performed within a 2-hour time window to minimize influence due to circadian rhythms. For each testing session, participants performed a graded cycling test on a Lode Excalibur bicycle ergometer (Lode, B.V.; $\mathrm{NL}$ ) until voluntary exhaustion. During these three tests, subjects either wore no mask (control), a surgical 
mask or a taped face mask. To avoid potential serial effects, the order of three mask conditions were randomized. The exercise protocol began at a workload intensity of 50 watts $(W)$. After every 3 minutes, the load intensity increased by $25 \mathrm{~W}$ in a step manner. The test was terminated either during subjective exhaustion, when subjects withdrew voluntary, or until subjects reached level 10 on the dyspnoea scale or stable $\mathrm{SpO}_{2}<80 \%$. The measured parameters included perception of breathlessness, heart rate, $\mathrm{SpO}_{2}$ and blood lactate concentration.

Dyspnoea (shortness of breath) rating. Subjects were asked to rate the dyspnoea that they perceived at the end of each stage, using the modified Borg dyspnoea scale (35) (Table 3).

Table 3

Modified Borg dyspnoea scale (35)

\begin{tabular}{|ll|}
\hline Rating & Corresponding breathlessness intensity \\
\hline 0 & No shortness of breath at all \\
\hline 0.5 & Very, very light (barely perceptible) \\
\hline 1 & Very light \\
\hline 3 & Mild \\
\hline 4 & Moderate \\
\hline 5 & Severe \\
\hline 6 & \\
\hline 8 & Very severe \\
\hline 9 & Very, very severe \\
\hline 10 & Maximal respiratory distress \\
\hline
\end{tabular}

Heart rate. Study participants wore a heart rate chest belt (Firstbeat Technologies Oy; FI) which continuously detects heart rate with a sampling frequency of $1 \mathrm{~Hz}$ throughout the graded exercise test. We used the Firstbeat SPORTS software tool (Version 4.7.3.1) to record the heart rate measurement. For the evaluation we determined the mean value of the detected signals of the last 30 seconds of each stage.

Oxygen saturation $\left(\mathrm{SpO}_{2}\right)$ was measured by a pulse oximeter on a fingertip (Nonin $8000 \mathrm{~A}$, USA) with a sampling frequency of $5 \mathrm{~Hz}$. We used the Lode Ergometry Manager software (version 10.6.0) to record oximeter data. 
Lactate. To measure the metabolic response to exercise, $20 \mu \mathrm{l}$ of capillary blood was taken from the earlobe of the subjects to determine the lactate levels. Blood was collected once at rest, at the end of each exercise stage, upon termination of the test, and at 1, 3, and 5 minutes after the end of the test. Subsequently, we determined the lactate values amperometrically using Biosen S Line device (EKF; GER). The lower detection limit of the instrument was a blood lactate concentration of $0.5 \mathrm{mmol} / \mathrm{L}$.

Mask questionnaire. After completing the graded exercise test wearing a clinical mask or a tape mask, study participants provided feedback on their subjective well-being and evaluation of the masks during the test by answering a questionnaire. The content of the questionnaire was modified from the questionnaire that other studies used $(23,36)$ (Table 4$)$. The questionnaire recorded subjective ratings and qualitative information about the comfort and wearability of the taped and surgical mask during the exercise test. Thereby the subjects could evaluate 11 questions on a visual analogue scale from 0 (totally disagree) to 10 (totally agree) and provide comments in an additional field.

Table 4

Content of the mask questionnaire. Adapted from $(23,36)$.

\begin{tabular}{|ll|}
\hline Question & Statement \\
\hline 1 & The general condition of your daily form is very good today \\
\hline 2 & The facemask prevents you from your maximal performance \\
\hline 4 & The facemask fits very well \\
\hline 5 & The wearing comfort of the facemask is very good \\
\hline 7 & The facemask material feels very good on the skin \\
\hline 9 & The sense of smell with the facemask is very good \\
\hline 10 & Breathing is very difficult with the facemask \\
\hline 11 & The heat generated with the facemask is very low \\
\hline
\end{tabular}

Statistics. For statistical evaluation, we used JASP software tool (version 0.12.0) to conduct the statistical analysis. As the duration of three exercise tests varied across conditions, for appropriate analysis of our exercise variables (perception of breathlessness, heart rate, blood lactate concentration and oxygen saturation) with a comparable exercise intensity, data was normalized, interpolated, and expressed in relative to individual peak power achieved (percentage of peak power) in the control condition. The exercise variables were assessed by one or two-way ANOVA for repeated measures to best 
answer our stated research questions. If there was a significant main effect, we used Bonferroni post-hoc tests for multiple comparisons.

To examine if there were differences between the ratings for surgical mask and taped mask from the mask questionnaire, paired t-tests were done to each domain of the questionnaire. For secondary analysis, we added gender as a between-group factor to evaluate if there was a gender difference in all analyses. Significance level was accepted as $p<0.05$ for all statistical tests.

\section{Results}

As part of this study, eight participants completed three graded exercise tests each with no adverse effects that required ending an experiment prematurely. Subjects achieved maximal workloads of $278 \pm$ $56 \mathrm{~W}(100 \%)$ with no mask, $269 \pm 56 \mathrm{~W}(97 \pm 6 \%$ of the no mask maximum) with a surgical mask and $247 \pm 56 \mathrm{~W}(88 \pm 6 \%$ of the no mask maximum) with a taped face mask. (Main effect: $F(2,14)=11.286, p$ $=0.001$.) The achieved maximal workloads were significantly less with a taped mask than with a surgical mask $(p=0.018)$ or no mask $(p=0.001)$. We now state and answer the three research questions of this study.

\section{Up to what intensity can subjects exercise with a taped face mask without the perception of major breathlessness and/or a drop in the oxygen saturation $\left(\mathrm{SpO}_{2}\right)$ to below $80 \%$ ?}

We arbitrarily defined dyspnoea ratings equal or above 7 (very severe) in the modified Borg dyspnoea scale as major breathlessness. Overall, with a taped mask subjects reached a rating of major breathlessness (i.e. "7") at $12 \pm 9 \%$ lower workload than with no mask $(p=0.012)$. Specifically, males rated dyspnoea 7 (very severe) at $65 \pm 7 \%$ of peak performance with the taped mask, at $69 \pm 10 \%$ with a surgical mask and $78 \pm 12 \%$ in the control trial with no mask. Females reached a rating of 7 (very severe) at $71 \pm 7 \%$ with the taped mask, $78 \pm 12 \%$ with the surgical mask and $82 \pm 7 \%$ of peak performance with no mask (Fig. 2).

Impairing ventilation may lower the blood $\mathrm{O}_{2}$ saturation $\left(\mathrm{SpO}_{2}\right)$ and so we also tested the effect of the taped mask on $\mathrm{SpO}_{2}$ by pulse oximetry. Overall, participants' $\mathrm{SpO}_{2}$ values at $65 \%$ maximal workload were significantly lower when wearing the taped mask than wearing no mask $(p=0.018)$ (Fig. 3). In general, $\mathrm{SpO}_{2}$ responses to exercise varied greatly in-between subjects. They dropped to below $85 \%$ in two subjects, and the mean minimal values reached were $92 \pm 3 \%$ without wearing a mask, $90 \pm 6 \%$ when wearing the surgical mask and $89 \pm 4 \%$ when wearing the taped mask. Only in one participant (ID 5 in Fig. 3) the saturation dropped slightly below $80 \%$ but recovered within seconds and reached $92 \%$ at the end of the test. Therefore, this temporary drop did not reach abortion criteria of the test.

How does a taped mask affect heart rate and blood lactate during a graded cycle ergometer test when compared to a surgical mask and no mask? 
Figure 4 shows average heart rate and lactate concentration data during the three exercise conditions, expressed relative to the maximal workload achieved in the no-mask test. There were no significant differences in the heart rate and lactate concentration at any workload, but subjects achieved the highest lactate concentrations with no mask.

\section{How comfortable is an adhesive mask during a cycling ergometer stage test compared to a surgical mask?}

When compared to wearing a surgical mask, subjects felt that the taped masks were more comfortable $(p=0.038)$, felt better on the skin $(p=0.004)$, reduced the sensation of moisture $(p=0.026)$ and subjects had a reduced perception of heat $(p=0.021)$ during the graded exercise test (Fig. 5).

In five out of eight participants the taped face mask partially detached during high exercise intensities. Typically, these were small gaps between the adhesive tape and skin after $20.4 \pm 3.3$ minutes at $210 \pm 22$ W. Qualitative feedback provided by the participants are listed in additional file 1.

\section{Discussion}

The main finding of this study is that a taped face mask significantly reduces the maximal workload in a graded exercise test by $12 \pm 6 \%$ when compared to no mask. This is no surprise as a well-sealed, taped filter mask will increase breathing resistance. However, a taped mask is tolerated well during mild to moderate exercise and is more comfortable to wear than a surgical mask.

Perceived breathlessness and drop in oxygen saturation. Participants wearing a taped mask perceived major breathlessness (subjectively defined as a dyspnoea scale rating of 7 or above) earlier, at $12 \pm 9 \%$ lower exercise intensity when compared to no mask. This might result from the potentially higher breathing resistance (not measured) because of the better sealing of the taped mask. We found, however, no statistical difference in minimal $\mathrm{SpO}_{2}$ during the exercise tests. One male subject transiently reached a $\mathrm{SpO}_{2}$ of $75 \%$ at $83 \%$ of the maximal workload while wearing a surgical mask. However, the $\mathrm{SpO}_{2}$ recovered quickly and rose to $92 \%$ at the end of the test. The experimenters decided to continue with the test as they interpreted this brief decline to below the cut off of $80 \%$ as a technical error. Precision and accuracy of $\mathrm{SpO}_{2}$ readings can be affected by technical problems, poor perfusion (e.g. a cold finger) or environmental factors such as movement artefacts $(37,38)$.

Whilst other studies found no differences between no mask and masks in terms of oxygen saturation (21, 28,29 ) or partial pressure of oxygen (23) during exercise, we observed a significantly lower $\mathrm{SpO}_{2}$ at $65 \%$ of the maximal workload when compared to no mask. However, the $\mathrm{SpO}_{2}$ drop was only $1.5 \%$ which should be only a minor difference physiologically $\left(\mathrm{SpO}_{2}\right.$ at $65 \%$ was no mask: $95.2 \pm 1.8 \%$, surgical mask $94.3 \pm 1.4 \%$, taped mask $93.7 \pm 1.9 \%$ ).

Heart rate and lactate concentration. We found no significant difference in the heart rate or lactate concentration at any exercise intensity from rest to $90 \%$ of the maximal workload. This is consistent with 
other studies that compared wearing face masks to no mask during graded exercise tests $(21,28,29)$. Two studies $(7,26)$, however, reported significantly higher heart rates when exercisers wore a surgical mask than when not wearing a mask. Also, Li et al. (36) measured a higher heart rate when wearing N95 face mask than surgical mask during various walking intensities. Different subjects, exercise modalities, face masks and intensities may explain these differences. Subjects reached a higher peak lactate concentration when wearing no mask. This is primarily explained by the higher workload that the subjects achieved when wearing no mask which is consistent with another study (23).

Mask comfort. Subjects that wore a taped face mask felt more comfortable, the taped mask felt better on the skin and had a reduced sense of moisture or heat from the mask during exercise when compared to wearing a surgical mask. In another study, Li et al. (36) compared subjective sensations of N95 and surgical face masks during intermittent exercise on a treadmill. They found that participants felt that the surgical mask was drier, cooler, easier to breathe and more comfortable when compared to a N95 mask. Our study is the first to test on the taped filter mask. Even though we did not compare it to N95 or FFP2 masks, taking into account of our data and the results of Lt et al. (36), wearing a taped mask during exercise could feel more comfortable than wearing other masks types.

In some of the experiments, the taped mask loosened partially and there were gaps between the tape and the skin. This could be a result of the movement of the mouth and nose because of deep breathing in combination with sweating. To ensure good tape adhesion, male users should therefore shave their face before exercise, and participants should avoid makeup or skin creams. We observed a poor mask adhesion in two male participants at their chin. It is unclear whether this was due to beard growth or because of the shape of the face. Some participants commented that the taped face mask is suitable for light and moderate exercise but not during maximal exercise.

Limitations. We did not measure ventilation in our study as a spirometry mask would have affected moisture build-up and thereby the property of face masks worn below a spirometry mask. Testing with a spirometry mask would also reduce external validity of our experiments. Also, we had a small sample size since we only investigated 4 males and 4 females which performed three tests each in randomised order.

\section{Conclusions}

In summary, taped face masks are tolerated well during mild and moderate exercise but they reduce maximal exercise capacity when compared to no mask. Subjects reported that they are more comfortable to wear during sport than a surgical mask and they are a new tool to avoid becoming infected by SARSCoV-2 and other infectious agents e.g. during fitness training in a gym, during sports such as martial arts and in occupations that require well sealing, comfortable face masks. Future variants of taped face masks could have a stronger adhesive e.g. for martial arts or long-duration sports and may include technical solutions to allow drinking during sport.

\section{List Of Abbreviations}


COVID-19, coronavirus disease 2019. SARS-CoV-2, Severe Acute Respiratory Syndrome Coronavirus-2. FFP2, filtering facepiece 2 . $\mathrm{SpO}_{2}$, peripheral capillary oxygen saturation. SD, Standard deviation. W, watts.

\section{Declarations}

\section{Ethics approval and consent to participate}

This study was approved by the ethical committee of the Technical University of Munich (Approval No. $584 / 20$ S). All participants signed an informed consent.

\section{Consent for publication}

Consent for publication of the mask images has been obtained from the individual.

\section{Availability of data and materials}

The datasets used and/or analysed during the current study are available from the corresponding author on reasonable request.

\section{Competing interests}

This study was funded by TRC The Rendering Company GmbH and we agreed the aims of the study with the company. None of the authors received direct payments from TRC The Rendering Company GmbH.

\section{Funding}

TRC The Rendering Company GmbH funded this project with the taped mask, and the expenses for participant's medical screening.

\section{Authors' contributions}

HW and MS designed, coordinated, supervised the study and drafted the manuscript. JT designed, coordinated, conducted the experiments and drafted the manuscript. HLN coordinated, conducted the experiments, prepared the figures, conducted statistical analysis, and drafted the manuscript. All authors reviewed and approved the final manuscript.

\section{Acknowledgements}

Not applicable.

\section{References}

1. Huang C, Wang Y, Li X, Ren L, Zhao J, Hu Y, et al. Clinical features of patients infected with 2019 novel coronavirus in Wuhan, China. The Lancet. 2020;395(10223):497-506. 
2. WHO. WHO Coronavirus (COVID-19) Dashboard 2021 [updated 1 June 2021; cited 1 June 2021].

3. CDC. Ways COVID-19 Spreads 2020 [updated 28 October 2020; cited 25 March 2021].

4. WHO. Coronavirus disease (COVID-19): How is it transmitted? 2020 [updated 20 October 2020; cited 25 March 2021].

5. Bahl P, Doolan C, De Silva C, Chughtai AA, Bourouiba L, Maclntyre CR. Airborne or droplet precautions for health workers treating COVID-19? The Journal of Infectious Diseases. 2020.

6. Kähler CJ, Hain R. Flow analyses to validate SARS-CoV-2 protective masks. Institute of Fluid Mechanics and Aerodynamics: Neubiberg, Germany. 2020:25.

7. Wong AYY, Ling SKK, Louie LHT, Law GYK, So RCH, Lee DCW, et al. Impact of the COVID-19 pandemic on sports and exercise. Asia-Pacific Journal of Sports Medicine, Arthroscopy, Rehabilitation and Technology. 2020;22:39-44.

8. van Doremalen N, Bushmaker T, Morris DH, Holbrook MG, Gamble A, Williamson BN, et al. Aerosol and Surface Stability of SARS-CoV-2 as Compared with SARS-CoV-1. New England Journal of Medicine. 2020(382):1564-7.

9. Wackerhage H, Everett R, Krüger K, Murgia M, Simon P, Gehlert S, et al. Sport, exercise and COVID-19, the disease caused by the SARS-CoV-2 coronavirus. Deutsche Zeitschrift für Sportmedizin. 2020;71(5):e1-12.

10. Dhillon M. Olympics in the time of a pandemic. Indian Journal of Orthopaedics. 2020;54:231-2.

11. Chu DK, Akl EA, Duda S, Solo K, Yaacoub S, Schünemann HJ, et al. Physical distancing, face masks, and eye protection to prevent person-to-person transmission of SARS-CoV-2 and COVID-19: a systematic review and meta-analysis. The Lancet. 2020;395(10242):1973-87.

12. Howard J, Huang A, Li Z, Tufekci Z, Zdimal V, van der Westhuizen H-M, et al. An evidence review of face masks against COVID-19. Proceedings of the National Academy of Sciences. 2021;118(4).

13. Leung NH, Chu DK, Shiu EY, Chan K-H, McDevitt JJ, Hau BJ, et al. Respiratory virus shedding in exhaled breath and efficacy of face masks. Nature Medicine. 2020;26(5):676-80.

14. Santos-Silva PR, Greve JMDA, Pedrinelli A. During the coronavirus (covid-19) pandemic, does wearing a mask improve or worsen physical performance? Revista Brasileira de Medicina do Esporte. 2020;26(4):281-4.

15. Wang $Y$, Tian $H$, Zhang L, Zhang M, Guo D, Wu W, et al. Reduction of secondary transmission of SARS-CoV-2 in households by face mask use, disinfection and social distancing: a cohort study in Beijing, China. BMJ Global Health. 2020;5(5):e002794.

16. Doung-Ngern $P$, Suphanchaimat $R$, Panjangampatthana A, Janekrongtham $C$, Ruampoom $D$, Daochaeng N, et al. Case-control study of use of personal protective measures and risk for SARSCoV 2 infection, Thailand. Emerging Infectious Diseases. 2020;26(11):2607.

17. Scheid JL, Lupien SP, Ford GS, West SL. Commentary: physiological and psychological impact of face mask usage during the COVID-19 pandemic. International Journal of Environmental Research and Public Health. 2020;17(18):6655. 
18. Abbott BW, Greenhalgh M, Clair SIS, Bush J. Making sense of the research on COVID-19 and masks. Abbott Lab Of Ecosystem Ecology. 2020.

19. Watson A, Haraldsdottir K, Biese K, Goodavish L, Stevens B, McGuine T. The association of COVID-19 incidence with sport and face mask use in United States high school athletes. medRxiv. 2021.

20. Chan NC, Li K, Hirsh J. Peripheral oxygen saturation in older persons wearing nonmedical face masks in community settings. JAMA. 2020;324(22):2323-4.

21. Epstein D, Korytny A, Isenberg $Y$, Marcusohn E, Zukermann R, Bishop B, et al. Return to training in the COVID-19 era: The physiological effects of face masks during exercise. Scandinavian Journal of Medicine \& Science in Sports. 2021;31(1):70-5.

22. Eroglu H, Okyaz B, Türkçapar Ü. The effect of acute aerobic exercise on arterial blood oxygen saturation of athletes. Journal of Education and Training Studies. 2018;6(n9a):74-9.

23. Fikenzer S, Uhe T, Lavall D, Rudolph U, Falz R, Busse M, et al. Effects of surgical and FFP2/N95 face masks on cardiopulmonary exercise capacity. Clinical Research in Cardiology. 2020;109(12):152230 .

24. Haraf RH, Faghy MA, Carlin B, Josephson RA. The physiological impact of masking Is insignificant and should not preclude routine use during daily activities, exercise, and rehabilitation. Journal of Cardiopulmonary Rehabilitation and Prevention. 2021;41(1):1.

25. Hopkins SR, Dominelli PB, Davis CK, Guenette JA, Luks AM, Molgat-Seon Y, et al. Face masks and the cardiorespiratory response to physical activity in health and disease. Annals of the American Thoracic Society. 2021;18(3):399-407.

26. Lässing J, Falz R, Pökel C, Fikenzer S, Laufs U, Schulze A, et al. Effects of surgical face masks on cardiopulmonary parameters during steady state exercise. Scientific Reports. 2020;10(1):1-9.

27. Pifarré F, Zabala DD, Grazioli G, i Maura IdY. COVID-19 and mask in sports. Apunts Sports Medicine. 2020;55(208):143-5.

28. Shaw K, Butcher S, Ko J, Zello GA, Chilibeck PD. Wearing of cloth or disposable surgical face masks has no effect on vigorous exercise performance in healthy individuals. International Journal of Environmental Research and Public Health. 2020;17(21):8110.

29. Ahmadian M, Ghasemi M, Nasrollahi Borujeni N, Afshan S, Fallah M, Ayaseh $H$, et al. Does wearing a mask while exercising amid COVID-19 pandemic affect hemodynamic and hematologic function among healthy individuals? Implications of mask modality, sex, and exercise intensity. The Physician and Sportsmedicine. 2021:1-12.

30. Loe H, Steinshamn S, Wisløff U. Cardio-respiratory reference data in 4631 healthy men and women 20-90 years: the HUNT 3 fitness study. PloS one. 2014;9(11):e113884.

31. Clark JM, Hagerman FC, Gelfand R. Breathing patterns during submaximal and maximal exercise in elite oarsmen. Journal of Applied Physiology. 1983;55(2):440-6.

32. Di Paco A, Catapano GA, Vagheggini G, Mazzoleni S, Micheli ML, Ambrosino N. Ventilatory response to exercise of elite soccer players. Multidisciplinary Respiratory Medicine. 2014;9(1):1-5. 
33. Mazic S, Lazovic B, Djelic M, Suzic-Lazic J, Djordjevic-Saranovic S, Durmic T, et al. Respiratory parameters in elite athletes-does sport have an influence? Revista Portuguesa de Pneumologia (English Edition). 2015;21(4):192-7.

34. Glass DJ. A critique of the hypothesis, and a defense of the question, as a framework for experimentation. Clinical chemistry. 2010;56(7):1080-5.

35. Büsching G. Wenn die Luft wegbleibt. Physiopraxis. 2009;7(02):40-1.

36. Li Y, Tokura H, Guo Y, Wong A, Wong T, Chung J, et al. Effects of wearing N95 and surgical facemasks on heart rate, thermal stress and subjective sensations. International Archives of Occupational and Environmental Health. 2005;78(6):501-9.

37. Ascha M, Bhattacharyya A, Ramos JA, Tonelli AR. Pulse oximetry and arterial oxygen saturation during cardiopulmonary exercise testing. Medicine and Science in Sports and Exercise. 2018;50(10):1992.

38. Kacmarek R, Stoller J, Heuer A. Analysis and monitoring of gas exchange. Egan's Fundamentals of Respiratory Care 10th ed Mosby. 2012:398.

\section{Figures}
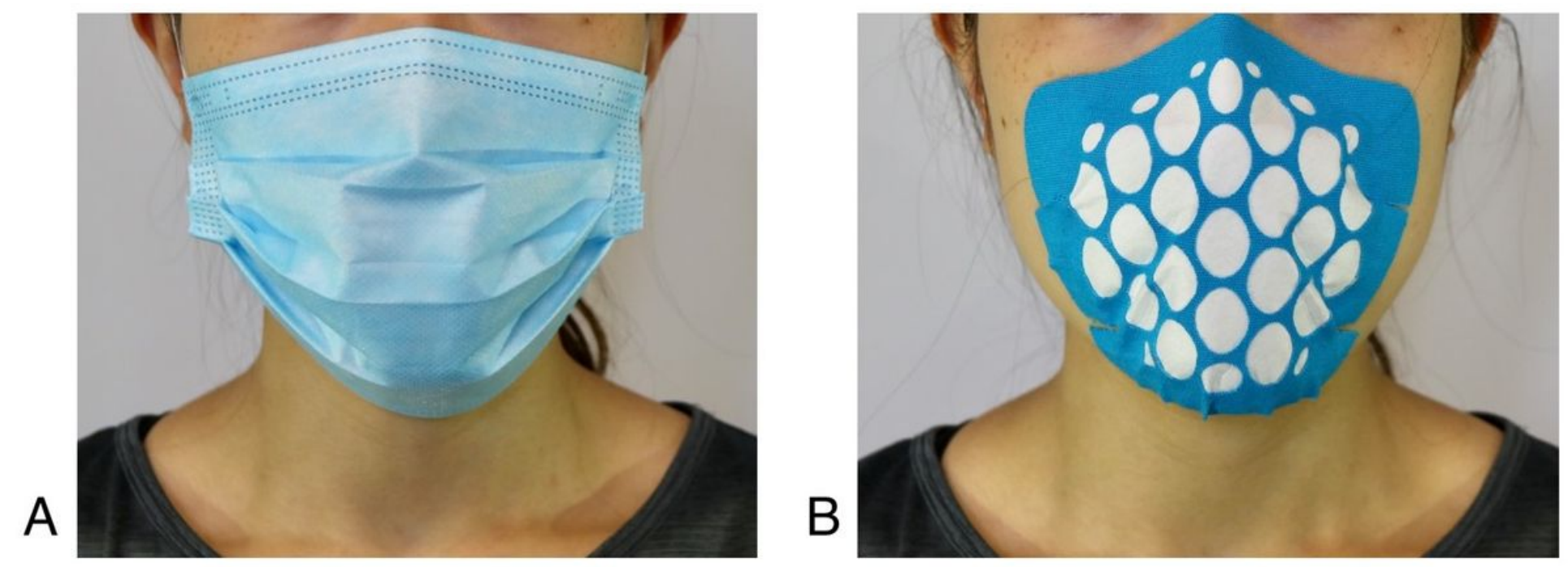

\section{Figure 1}

Photos of participant wearing (A) a surgical mask and (B) a taped filter mask. 

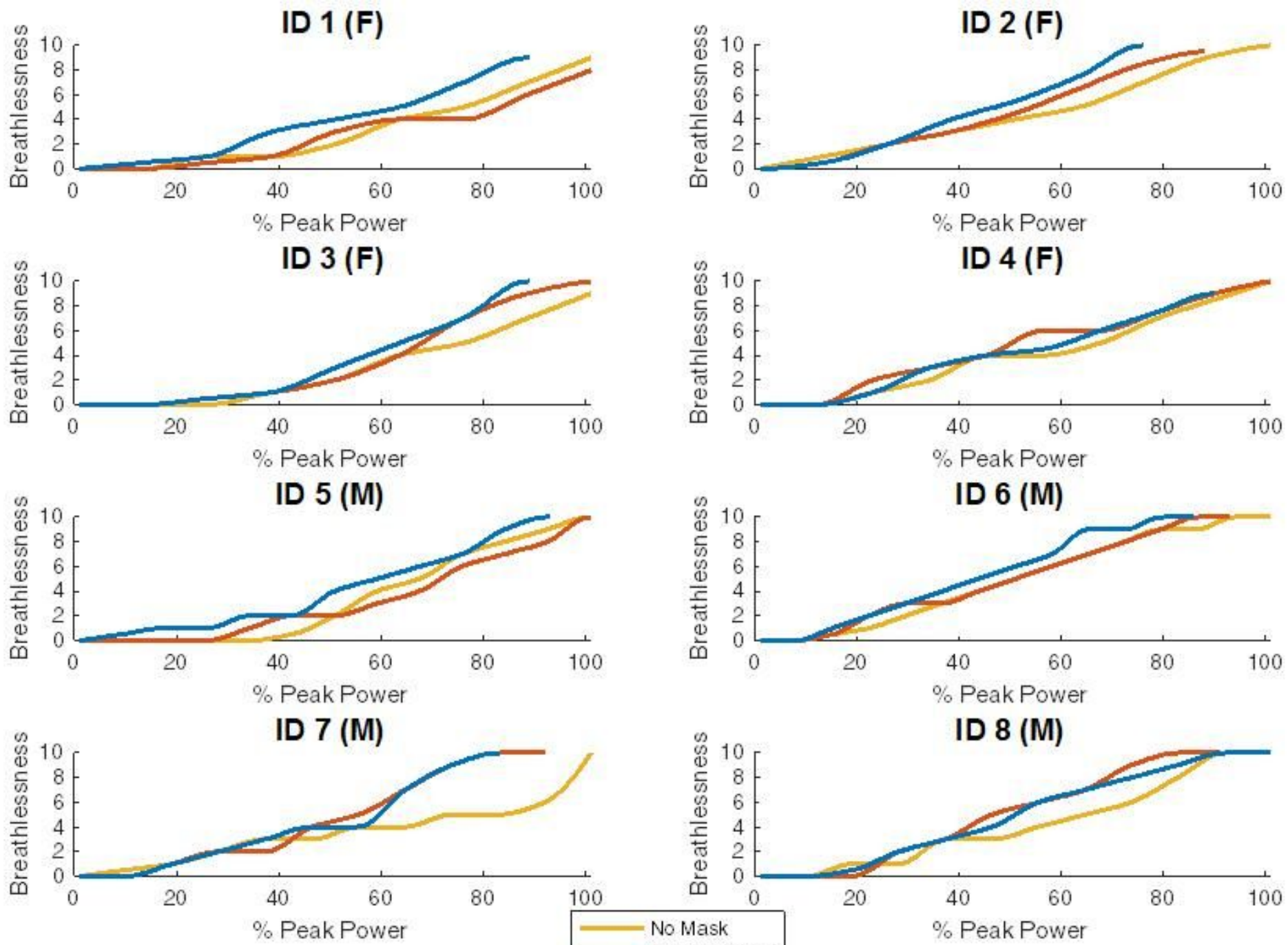

ID 8 (M)

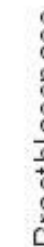

PeakPower

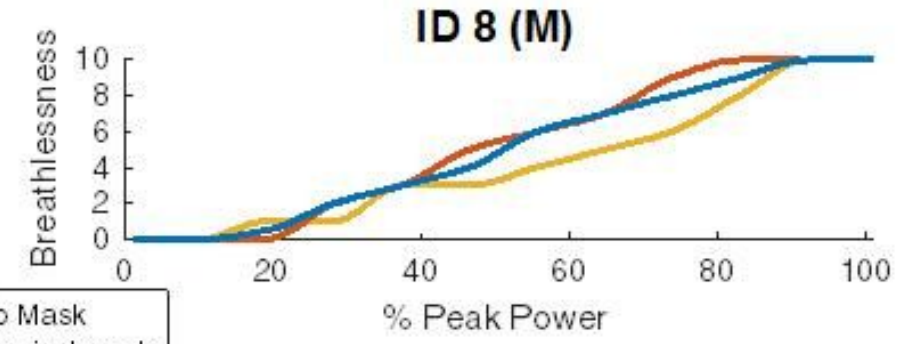

\section{Figure 2}

Individual ratings of the modified Borg dyspnoea scale during graded exercise tests. Data are expressed relative to the maximal workload achieved in the control (no mask) condition. Gender is indicated after the subject's ID: M=male and $\mathrm{F}=$ female. Black horizontal dotted lines indicate the breathlessness threshold of 7 (very severe). Main effect on mask factor: $F(2,14)=5.998, p=0.013$. Taped mask in comparison to no mask: $p=0.012$. No significant differences were found between gender $(F(1,6)=1.362$, $p=0.288)$ or mask $\times$ gender interaction $(F(2,12)=0.163, p=0.852)$. 

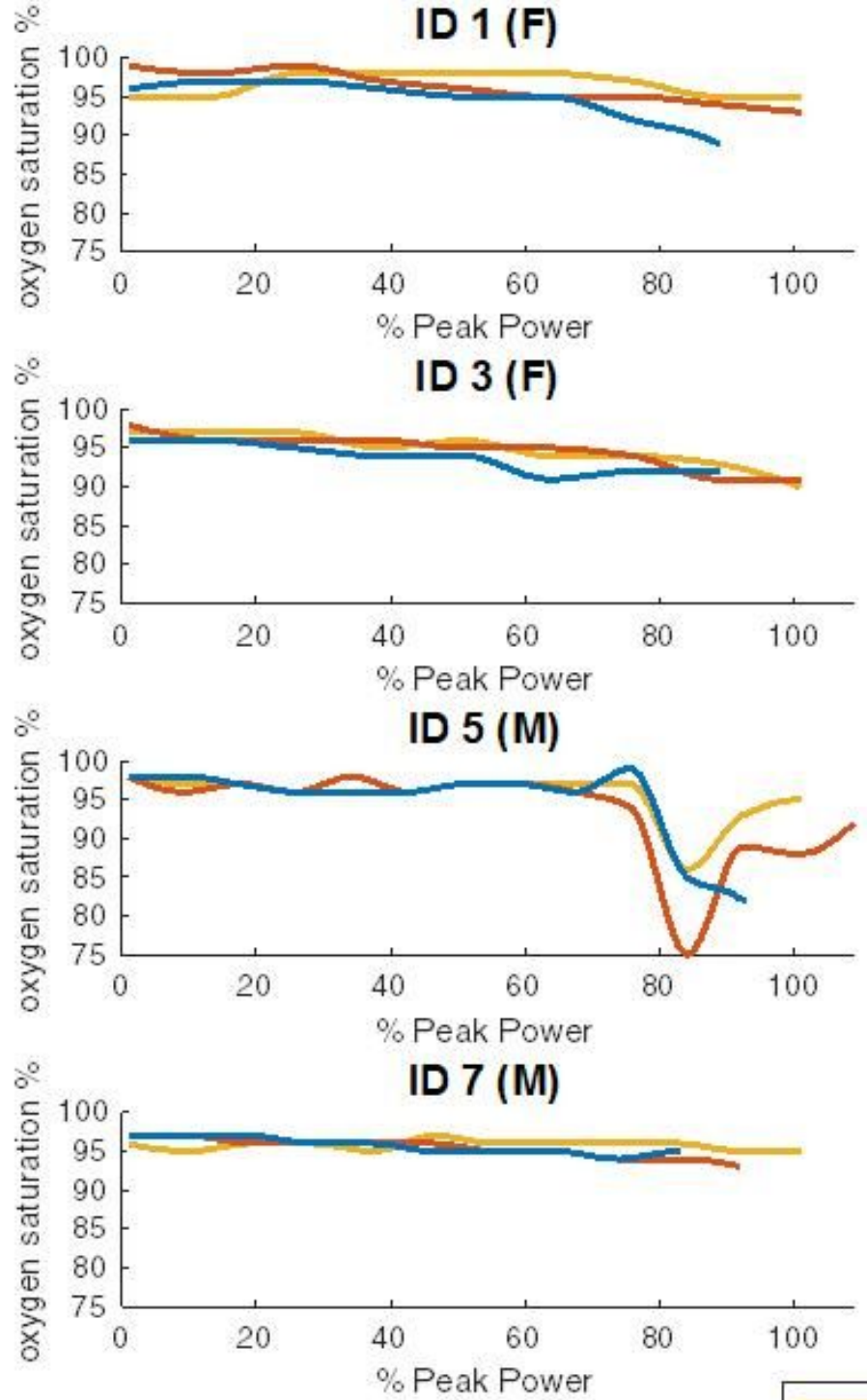

No Mask

Surgical mask

Taped mask
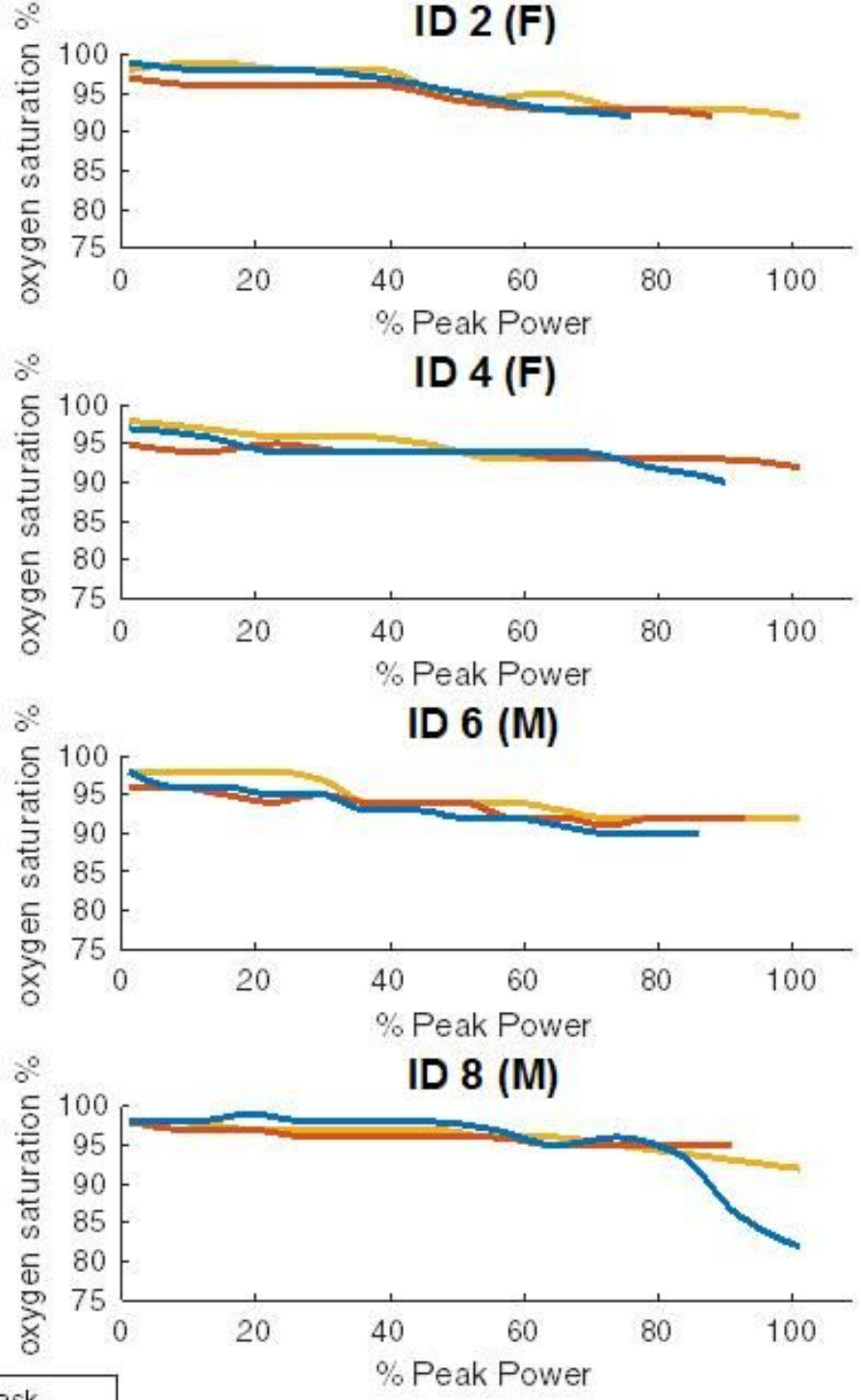

\section{Figure 3}

Individual Sp02 values during three graded exercise tests. Gender is indicated after the subject's ID: $\mathrm{M}=$ male and $\mathrm{F}=$ female. There were no statistical findings for minimal $\mathrm{SpO} 2$ values between the three mask conditions $(F(2,14)=1.742, p=0.211)$, gender factor $(F(1,6)=0.898, p=0.380)$ or mask $\times$ gender interaction $(F(2,12)=0.367, p=0.700)$. 

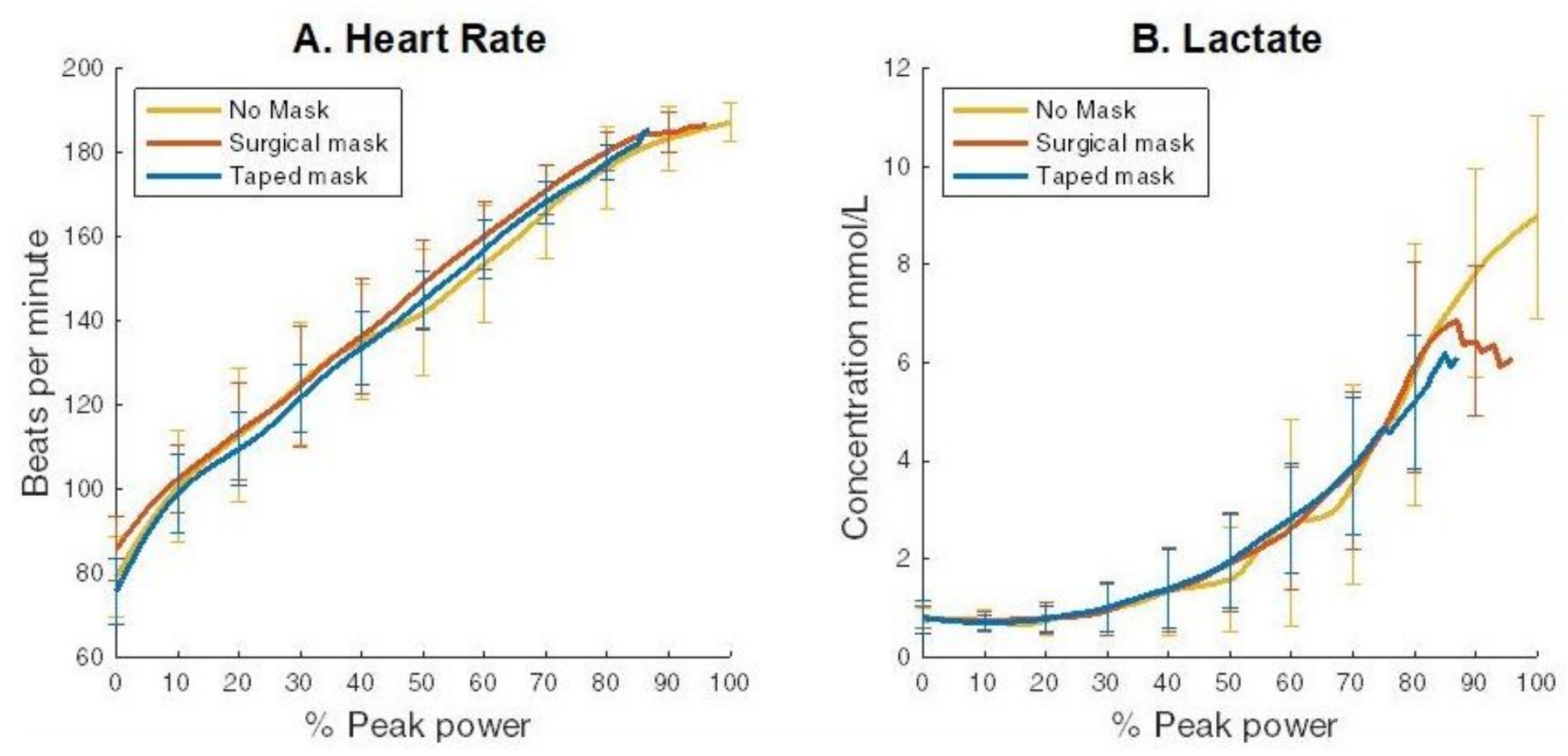

\section{Figure 4}

Heart rate and lactate concentration during graded exercise tests. One-way repeated measures ANOVAs were done to each parameter at each normalised workload in a $5 \%$-interval (e.g. at $0 \%$ peak power, $5 \%$ peak power etc.). We performed statistical tests until $90 \%$ of peak power because some trials did not reach beyond this percentage of maximal workload, therefore there was not enough data for statistical analysis. We found no differences between three mask conditions in heart rate and lactate concentrate from $0 \%$ to $90 \%$ peak power ( $p>0.05$ ). Note that heart rate data from all three tests of two participants were excluded due to technical error. The peak lactate concentration reached throughout the tests were $9 \pm 2 \mathrm{mmol} / \mathrm{L}$ with no mask, $7.8 \pm 1.4 \mathrm{mmol} / \mathrm{L}$ with surgical mask and $6.6 \pm 2.0 \mathrm{mmol} / \mathrm{L}$ when wearing a taped face mask (Main effect $F(2,14)=6.356, p=0.011$. Post-hoc no mask versus taped face mask $p=0.009$ ). 


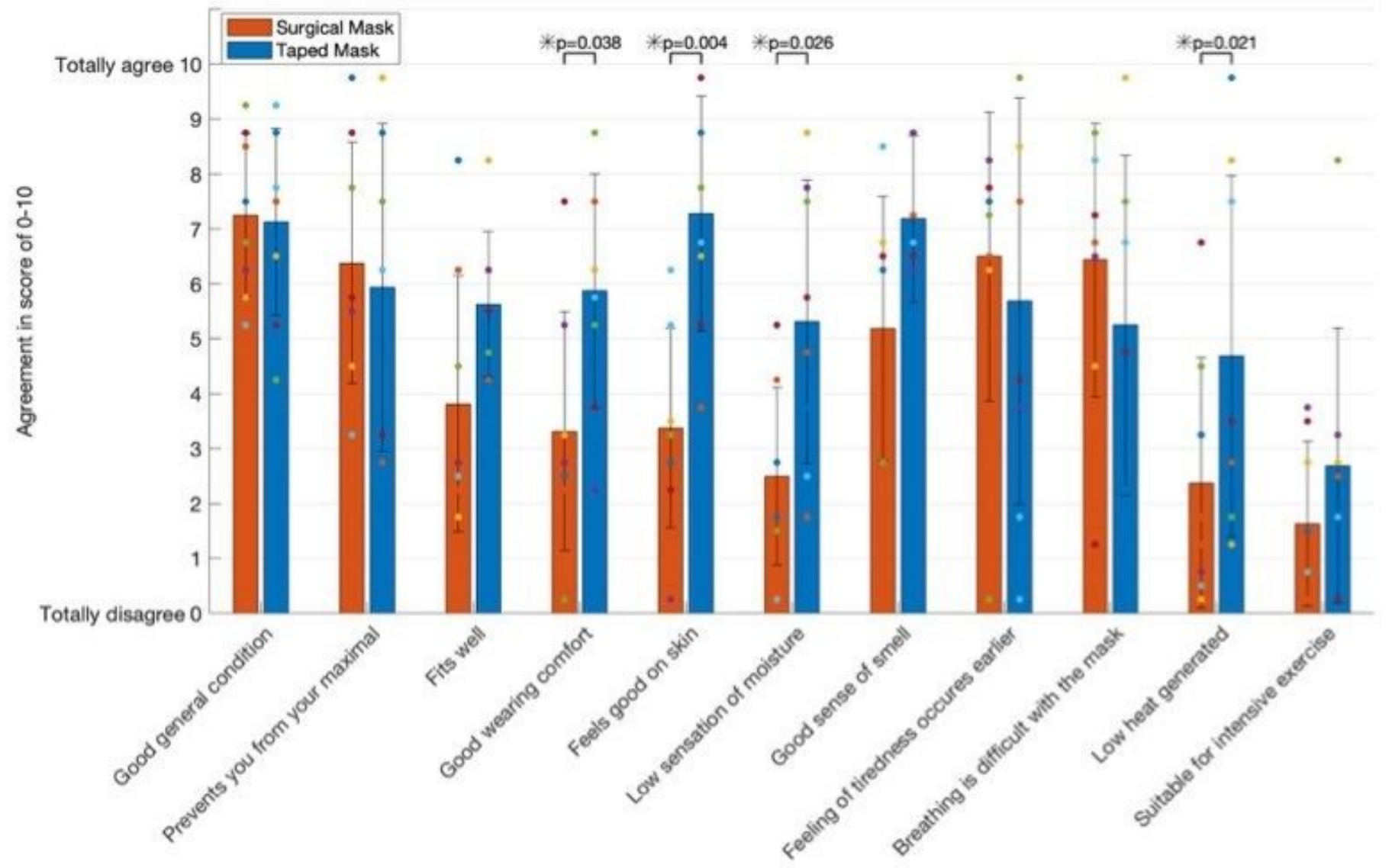

Figure 5

Results of the mask questionnaire. Data presented with means (bars), standard deviations (error bars) and individual ratings (colour dots) of the 11 statements. Data were generated using visual analogue scale $0-10$. For each of the statements from the questionnaire, a rating of zero indicated total disagreement on the statement and ten represented total agreement.

\section{Supplementary Files}

This is a list of supplementary files associated with this preprint. Click to download.

- Additionalfile1.xls 